\title{
A serial focus group model for understanding experiences of older adult volunteers and non-profit agency managers
}

\author{
Laura R. Bronstein ${ }^{1}$ and Susan E. Mason ${ }^{2}$
}

Research for this paper was partially supported by the Corporation for National and Community Service. All content included herein is the sole responsibility of the authors. Abstract: Serial focus group data shed light on the experiences of senior volunteers and nonprofit agency professional staff with the aim of maximizing the volunteer experience and contribution. Data were analyzed using a serial focus group approach to suggest pathways towards increasing mutual benefits. Themes from both volunteers and non-profit professionals included the need for better utilization of volunteers, the importance of communication and the advantage of defining roles at the beginning of the volunteer experience. Data from the groups also highlighted the need for planning on the part of the nonprofit staff and flexibility from the volunteers. Discussion and implications follow the report on the data.

Keywords: support work groups; focus groups; group research; civic engagement; civic service; nonprofit; older adults; volunteerism; retirees; group work; groupwork

1. Interim Dean, College of Community and Public Affairs. Binghamton University

2. Professor of Social Work and Sociology, Wurzweiler School of Social Work Yeshiva University

Address for correspondence: Binghamton University, Box 6000, Binghamton, NY 13902,USA.lbronst@binghamton.edu.masonse@yu.edu

Date of first (online) publication: 21st August 2013

Acknowledgement: Research for this paper was partially supported by the Corporation for National and Community Service. All content included herein is the sole responsibility of the authors.

Groupwork Vol. 23(2), 2013, pp.67-87. DOI: 10.1921/3901230201 


\section{Introduction}

This article reports on a civic service project that utilized serial focus groups to learn from retired volunteers and non-profit agency staff in a collaborative effort to provide both fulfilling experiences for retirees as well as needed services to agencies. Along with a presentation of data regarding the experiences of senior volunteers and non-profit staff, a discussion on the value of serial focus group research and its potential uses for data collection, program improvement, and participant support is offered with suggestions for future research.

We report on the civic service initiative funded by the Corporation for National and Community Service (CNCS) known as SmartWorks, designed to use groups as a means of understanding the needs of retired older adult volunteers and non-profit agency staff. Separate focus groups for volunteers and agency staff were run concurrently and presented with questions related to their experiences. The initial goal for running the groups was to draw out useful information on the best ways to match and assure meaningful experiences for senior volunteers and non-profit agency staff. A secondary goal became creating a positive experience for participants through the focus group experience. It soon became clear that the secondary goal took on equal importance with the initial goal as participants from the volunteers and agencies discussed how to resolve sensitive issues related to the volunteer project and used the time in the focus groups to support each other in this effort.

\section{Background}

\section{Civic service and civic engagement}

The distinction between civic engagement and civic service is that the former is social action to encourage change at local, national and international levels and civic service is a type of civic engagement, such as volunteering in a formal organization (Center for Social Development, 2008). The last decade and a half has seen a decline in civic service, often attributed to the large numbers of women, often mothers, who no longer volunteer but are instead part of the workforce (Butler $\&$ Eckart, 2007). While much has been written about youth and college 
students' civic engagement efforts (Carlson, 2006; Gant, Shimshock, Allen-Meares, Smith, Miller, Hollingsworth, \& Shanks, 2009; Mulroy, 2004), the literature is also beginning to note the challenges of organized volunteerism, civic service, by older adults (Bowen, Martin, Mancini, \& Nelson, 2001; Butler \& Eckart, 2007; Freedman, 1997, 1999; Nicotera, 2008).

Freedman (1999) refers to older Americans as our 'only increasing natural resource' (p.17) and describes the potential of the growing number of older adults to fill the vacuum left by increased needs and recent declines in civic service (Freedman, 1997). As a way to address both the interests of the burgeoning numbers of retired older adults and the needs of non-profit agencies where funding cuts have affected service provision, civic service can be a critical part of the solution (Lie, Baines \& Weelock, 2009; McBride, Sherraden, Benitez, \& Johnson, 2004). Although the bulk of service opportunities today are geared towards young persons, the potential for having older volunteers work on agency and community projects is enormous. Researchers in the field agree that what is needed is a balanced view where both older adults and agencies/communities stand to gain from activating a planned means of conducting civic engagement in the form of civic service activities (Morrow-Howell, 2006; Morrow-Howell \& Tang, 2007).

Despite excellent examples of civic service/civic engagement programs with far-reaching benefits (for example, Experience Corps, Civic Ventures, National Senior Service Corps, Volunteers in Medicine), there has been a dearth of published work that provide a theoretical framework to assesses its value and outcomes. Researchers in the field of civic engagement/civic service have called for models along with supporting evidence that show efficacy (e.g., Macduff, Netting, \& OConnor, 2009; McBride, 2009; McBride, Sherraden, \& Menon, 2007; McBride et al, 2004; Wilson \& Rymph, 2006). This study begins to add to a developing knowledge base by reviewing the literature and reporting on the outcome of a series of facilitated focus groups consisting of retired volunteers and non-profit providers over a two-year period as part of the CNCS SmartWorks initiative. 
Laura R. Bronstein and Susan E. Mason

\section{Older adults and civic services}

Most of the literature on older adults has been devoted to needs for community-based care, attention to health disparities, inadequate numbers of service providers, and other issues that address the rising numbers and needs of frail elders (Burnette, Morrow-Howell, \& Chen, 2003; Institute of Medicine, 2001). At the same time it is also necessary to address the increasing older adult population that is vital, healthy and eager to enhance their own lives and those of others. In the United States today, older adults are now the largest, healthiest, and best-educated group of seniors in history (Romero \& Minkler, 2005). While many of these older adults report wanting to work for pay (Kanfer \& Ackerman, 2004), others may look for volunteer work that inherently carries with it less stress and often less responsibility (Romero \& Minker, 2005). Between 25\% - 30\% of older people in the United States do volunteer (Butler \& Eckart, 2007; Cohen-Callow, 2007; Corporation for National and Community Service (CNCS), 2007). Freedman (1999), one of the country's most articulate spokesmen for older adults as the centerpiece of civic engagement, argues the importance of creating institutions and opportunities to enhance the lives and contributions of volunteering adults post-retirement. These include structures for centralization of volunteer services (Thompson \& Wilson, 2001) in addition to supplemental services shown to have an impact on volunteering (for example, public transportation) (Narushima, 2005).

Building structures alone is only part of the equation, as today's baby boomers need to be recruited and asked to volunteer (Thompson $\&$ Wilson, 2001). Data show that more seniors will volunteer if only asked and those who already volunteer would give more hours if asked and if the opportunity is meaningful (Freedman, 1997). Older adults define meaningful opportunities in terms of what they are looking for from civic engagement in a variety of ways. Factors that do seem to be components of what many senior volunteers define as meaningful include contributing to the community, being part of a team and social interaction (Kovacs \& Black, 1999). Narushima (2005) found that volunteers in their fifties and sixties wanted to pay back prior generations for what they received, while older volunteers in their seventies wanted to make the world a better place for future generations; in addition, senior volunteers of all ages reported appreciating the opportunity to have input into the programs in which they are involved. 
Beyond a sense of meaning acquired through volunteering, research has shown an array of benefits in older adults' physical and mental health including cognitive and physical activity, social interaction and family functioning connected to their civic engagement and civic service (Fried, Carlson, Freedman, Frick, Glass, Hill et al, 2004; Greenfield \& Marks, 2003; Jirovec, 2005; Martinson \& Minkler, 2006; Romero $\&$ Minkler, 2005; Rosenburg \& Letrero, 2006; Schneider, Altpeter, \& Whitelaw, 2007). Clearly civic engagement that includes civic service by seniors has the potential for bringing about a good set of outcomes for volunteers. It can also be beneficial for non-profit agencies, especially in today's economic climate.

\section{Non-profit organizations and agencies}

Beginning in the early 1980s with changes in federal funding, nonprofit agencies have come to increasingly rely on the efforts of volunteers (Hinterlong \& Williamson, 2006). Currently, on-going declines in public expenditures to support non-profits have impacted their capacity to support the paid personnel necessary to do their work, raising the demand for volunteers (Tang \& Morrow-Howell, 2008). This is exacerbated by the concurrent increasingly complex needs of the clients that these organizations serve (Macduff, Netting, \& O'Connor, 2009). In looking towards older adults and civic engagement to help fill this gap, it is strongly suggested that we don't make volunteers the core of non-profit agencies, but instead create opportunities for them to be supported as vital components of the core (Windsor, Anstey \& Rodgers, 2008). These writers believe that social policy is best served by striking a balance of opportunities and support for older adult volunteers while ensuring that human services have adequate funding. Freedman (1997) believes that national service for seniors should be geared towards 'accomplishing important work directly liberating salaried professional staff to do their jobs better and more efficiently, and leveraging the efforts of new ranks of volunteers' (p.257). Although Freedman wrote when we as a nation were closer to full employment, even today, there are creative ways to integrate senior volunteers into agencies so that salaried jobs are not imperiled. A number of authors (e.g., Martinson \& Minkler, 2006; Theiss-Morse \& Hibbing, 2004) argue the importance of a strategic approach to senior civic engagement focusing beyond discrete

Groupwork Vol. 23(2), 2013, pp.67-87. DOI: 10.1921/3901230201 
volunteer activities, but on promoting civic engagement efforts such as political involvement that foster the needs of non-profit agencies when advocacy goals are trumped by lack of time.

\section{Agency staff support}

Once a non-profit agency decides to mount an effort to actively involve senior volunteers, staff must develop policies and structures to support their recruitment and retention; and develop orientation programs. Hong, Morrow-Howell, Tang, \& Hinterlong (2009) and Jirovec (2005) argue that these protocols are more likely to be successful when they maximize flexibility and choice so as to match volunteers' skills and personal needs with those of the agency. Jirovec's (2005) research shows that recruitment and retention of older adult volunteers are most successful when assignments are consistent with the volunteer's health status, desired activity and desired amount of hours. Assignments should take into account a volunteer's at-home responsibilities that may include family and/or friend caregiving and its requisite tasks and hours. While social interaction is shown to be a component that seniors value when volunteering, opportunities to complete work at home may also be an important recruitment and retention consideration when appealing to retirees with at-home commitments and/or limited transportation (Chambre, 1993).

As stated earlier, seniors are likely to volunteer when they are asked to do so (Thomson \& Wilson, 2001). Therefore nonprofit agencies interested in increasing senior volunteerism, need to market their efforts, especially when they are located in difficult to reach or crime ridden neighborhoods, or when they serve populations that are inherently different from the targeted volunteers (Marx, 1999). Such marketing can expect high levels of success when employing a variety of methods and mediums and when it highlights a broad range of opportunities and ways that volunteers' work will make a contribution (Thompson \& Wilson, 2001). In the less easily filled positions such as in some health settings, Marx (1999) suggests emphasizing positive outcomes for patients when they come into contact with volunteers, in order to attract seniors motivated by altruism. Orientation programs for recruited volunteers can be structured to socialize both volunteers and agency staff to their work and potential contribution. Professional 
staff at non-profit agencies can work alongside or supervise senior volunteers (Cohen-Callow, 2007). Because volunteer retention is tied to ongoing opportunities to contribute, the assigned tasks require thoughtful planning that can be adjusted to individual levels of ability and willingness to take on responsibility (Kovacs \& Black, 1999). In addition, because seniors have much to offer as well as to learn, successful assignments and training programs are best when they are interactive so that seniors can dialogue with and learn from each other (Romero \& Minkler, 2005). The bottom line is that all aspects of the volunteer experience need to be thought through and attended to so that it is experienced as successful by both the agency and the older adult. As Freedman (1997) states, '...people won't be happy volunteering unless adequate preparation, job development, support, and follow-through are present' (p.256).

\section{Serial focus groups}

The concept of serial focus groups is relatively new in the literature. Krueger and Casey (2000) refer to periodically repeated focus groups as important for providing continuous feedback, such as 'How are we doing?' or 'How can we improve?' (p.187). They see an advantage in running these groups for times when organizations need up-dated information on member perceptions and ways to make improvements. The authors suggest two different models: groups with different members but from the same organization responding to similar questions over time and the second model, keeping the same members, having them meet at intervals and tracking changes in perceptions. The latter model is the one adopted by this research where members became 'key informants,' a term used by Kreuger and Casey (2000) in their discussion of the interval model (p.188).

Researchers are undoubtedly using serial or repeated focus groups, but there are few discussions in the literature. One exception is Walton's (2009) study of mothers of sexually abused children in England. The author's use of serial focus groups with four women provided research data in a way that was viewed as both non-oppressive and supportive. The women were empowered by their ability to support each other. They decided what to reveal and they provided mutual aid to each other over the times they met. The serial nature of the groups allowed the

Groupwork Vol. 23(2), 2013, pp.67-87. DOI: 10.1921/3901230201 
women to get to know each other thereby allowing for these positive group dynamics to take place, a process that would be unlikely in a one-time focus group.

We could not find examples in the literature of concurrent serial focus groups conducted for the purpose of gaining information for program improvement and evaluation. It is likely that studies of community action projects may have used an adaptation similar to ours, but would have considered the groups to be conscious raising or empowering rather than focus groups (Abu-Samah, 2009).

\section{The study}

\section{Program description}

In addition to using focus groups for evaluation and continuing improvement, the SmartWorks program design was developed in 2005 from ideas also emerging from focus groups. This SmartWorks project began in January 2006 as a two-year program for informed, motivated and committed professionals who had retired and wanted to be involved as volunteers in their community in upstate New York. The goal of the SmartWorks project was to match the talents and abilities of retirees with newly created volunteer programs at local nonprofit organizations. To accomplish this goal, two waves of volunteers and nonprofit professional staff were recruited during each year - 2006 (Year I) and 2007 (Year II) - of the project. A training program was developed and delivered - one for volunteers and one for nonprofit staff - at the beginning of each of the two program years. For each of the two waves, serial focus group meetings were scheduled at three intervals for both the volunteers and the nonprofit agency staff. Groups were expected to provide on-going data for both evaluation and program improvement.

\section{Methodology}

\section{Sample}

Twenty- eight retirees attended one of the training events and became SmartWorks volunteers in Year I or II. Of these 28 volunteers, 17 were 
women and nine men; 24 were White with one African American, one Indian, one Hispanic and one Asian American; 27 of the volunteers were between the ages of 50-70 and one participant was over 80 . The educational level of volunteers ranged from high school graduates to those possessing MDs or PhDs; the majority were highly educated with most having earned at least a master's degree.

Twenty-one representatives from the nonprofit agencies participated in one of the training events in the two years and followed through in participating in the groups. Of the 21 nonprofit agency representatives, nineteen were women and two were men; almost all were White $(n=20)$; one African American; 19 were between the ages of 35-45 and two were over 45 .

\section{Procedure}

Researchers (Hong, Morrow-Howell, Tang, \& Hinterlong, 2009; Macduff, Netting \& O'Connor, 2008) suggest volunteer outcomes are influenced by both individual and institutional capacity, and thus the SmartWorks study described here reports on data from both individual volunteers and non-profit agency representatives. A total of 12 focus groups were held over the two years of the grant. Focus groups have an excellent potential for qualitative data collection (Padgett, 2008). Focus groups were held with Year I volunteers at three points in time (beginning, middle and end); Year II volunteers at the same three points in time; and with the nonprofit agency staff overseeing the volunteers at the same intervals - three focus groups with Year I nonprofit agency staff and three with Year II nonprofit staff. While participation varied slightly, the majority of program participants involved with SmartWorks attended and participated in their assigned focus groups. The duration of the focus groups ranged from approximately one to one and a half hours. An experienced researcher and groupworker facilitated the groups. Questions were geared to ascertain the participants' experiences with volunteering, their expectations, and how SmartWorks was and was not meeting their expectations. They were also asked for ideas for project improvement. The group facilitator/researcher attended each initial training session for both volunteers and nonprofit staff in order to discuss the evaluation and continuous improvement plan, gain participants' consent and answer any questions. With participants' consent, all focus groups were audio taped and transcribed for analysis

Groupwork Vol. 23(2), 2013, pp.67-87. DOI: 10.1921/3901230201 
as described below. University Institutional Review Board approval was obtained.

\section{Data Analysis}

Analysis of the qualitative data drew on principles of focus group research, which calls for systemic, sequential, verifiable and continuous data collection and coding (Krouger and Casey, 2000). Printed transcripts were independently reviewed and re-read several times by a researcher and an assistant specially trained in this method. Data were coded sequentially and continuously for emerging themes that were verifiable. Analytic induction, as described by Miles \& Huberman (1994), was employed for theme analysis where codes were identified and patterned to create themes; the themes were then continually tested and refined as the initial data were compared with newly collected data. Considering Padgett's (2008) discussion of rigor in qualitative research, the researchers engaged in 'observer triangulation' in which each independently reviewed the data and then discussed the theme formation/confirmation with each other several times. From this process, three themes emerged out of the six focus groups held with the volunteers; and three themes emerged out of the six focus groups held with the nonprofit agency staff. Each theme is identified with examples from the actual words of the participants who participated in the focus groups.

\section{Results}

\section{Focus groups with volunteers}

The following themes emerged out of the focus groups with the two cohorts of senior volunteers with regard to their experience with SmartWorks: 1.) The appreciation of the opportunity to develop new friendships, knowledge and skills; 2.) The request for better utilization of themselves as volunteers; and, 3.) The importance of having a responsive staff that are sensitive to their needs as volunteers.

Theme I: Volunteers: The appreciation of the opportunity to develop new friendships, knowledge and skills developed. One of the most valuable parts of the SmartWorks experience for the volunteers proved to be the 
'newness' and opportunities for learning it introduced into their lives. This came in the form of new skills and knowledge gained directly from their experience at the nonprofit organization as well as in the form of new friendships. Both the new friendships and opportunities to gain new knowledge and skills were equally valued. This helps expand the notion of what older adults define as 'meaningful' as being the chance to develop in ways they hadn't before. One man expressed how he viewed his experience as meaningful: 'I have the opportunity to meet new people and be a part of the community. I have the opportunity to learn new things and keep busy.'

The chance to develop new knowledge and skills and especially to be able to have work experiences that they had not previously known was seen as an important opportunity. A volunteer noted: 'All my life I've been teaching and I wanted to do some learning actually; you don't always want to do the same thing you have been trained to do.' Similarly, another volunteer commented on his ability to learn a new discipline and he saw an important benefit of his volunteer experience: 'My unexpected benefit is becoming an historian. Just to think there is something else besides chemistry and physics; .... I am learning a new field, a new discipline and I am learning from others.'

Theme II: Volunteers: The request for better utilization of volunteers. There was almost a unanimous agreement among volunteers that they could be better utilized if the nonprofit organization had a better means of utilizing their skills and knowledge. While volunteers spoke about the importance of flexibility, there was a concern that the agencies often lacked structure conducive to maximizing the volunteers' individual contributions. Although there were some who voiced the opposite concern, that they wanted to more fully broaden their perspectives, the majority wanted more deliberate application of their specific skills to transferable opportunities. Reflecting the literature on meaningful volunteering, the volunteers wanted their efforts to make a positive difference in the nonprofit agencies' work. Key statements that emerged from the focus groups included: 1) 'A lot of organizations can barely define a project... They need to be educated on what it takes to get the most out of volunteers'; 2) 'What if you had volunteers be part of the project development'; and, 3) The project needs more definition (paraphrase).

Theme III: Volunteers: The importance of having a responsive staff that are sensitive to the needs of the volunteers. Similar to senior volunteers' desire 
to make a contribution to the nonprofit agencies, it was important for them to feel listened to and respected by both the SmartWorks and agency staff and to feel that program design reflected and responded to their needs. The participating seniors were largely professionals who came from jobs that utilized their expertise and valued their contributions. It was not surprising that they felt a need to continue identifying themselves as professionals with much to offer. In this study, volunteers were mostly pleased with the way they were treated by the staff of Smartworks who were training and assigning them to the nonprofit agencies. Volunteers' needs were supported in several respects by Smartworks staff and included providing direct support and information, and linking volunteers with programs that suited their talents. One volunteer was pleased with the amount of support given to him by the SmartWorks staff person: 'I think XX (Program Director) is terrific. She doesn't overburden you and she knows just the right amount of contact and oversight.'

\section{Focus groups with nonprofits}

The following themes emerged out of the focus groups with the two cohorts of nonprofit professional staff with regard to their experience with SmartWorks: 1.) Senior volunteers met and exceeded expectations; and, 2.) Initial difficulties in defining roles were alleviated over the course of the experience. In addition, non-profit staff offered suggestions for better utilization of their time as trainers and managers of volunteers.

\section{Theme I: Nonprofits: Senior volunteers met and exceeded expectations}

The nonprofit staff overwhelmingly praised the volunteers for their contributions, their level of expertise and their willingness to give. They especially appreciated the volunteers' high degree of competence and their willingness to contribute to initiatives by presenting helpful ideas that assisted their agencies. Nonprofit staff expressed that the volunteers took some of the burden off their agencies that were under stress trying to accomplish all their goals with inadequate resources. The following are the exact words of the nonprofit staff about how the senior volunteers met and exceeded their expectations:

- We got capable, experienced, mature workers at no cost. We had 
well qualified people to do important tasks that can't be done otherwise.

- We gained the ability to obtain additional qualified volunteers who can assist us in implementing our programs.

- My caseworkers are thrilled to have XX as a part of our team... having the volunteer work on the XXX project takes a huge burden off their shoulders.

Several other positive quotes were obtained and can be summarized as volunteers accomplishing goals without needing much assistance, volunteers being a good fit in the organization, and volunteers exceeding expectations by offering new ideas for agency projects.

Theme II: Nonprofit agencies : Initial difficulties in defining roles were alleviated over the course of the experience

Nonprofit staff talked about the time it took to get to know what senior volunteers needed in their experience and to be able to deliver it. There were start-up 'costs' in terms of time and understanding the needs of both the group and individual volunteers. Nonprofit staff voiced frustrations around the efforts required to work in this context but expressed willingness to stay with it, learn and make accommodations where they could. An important lesson gained from the non-profit staff was that senior volunteer activities often call for a degree of flexibility, patience and a willingness to learn on the part of those managing these efforts. The non-profit focus group participants described their experiences in this regard as somewhat problematic in the beginning phases, but with additional attention, the outcomes became more positive. As one non-profit participant stated: 'We put in a description for a job...I guess there was a group of volunteers that looked at the application and their feedback was that it wasn't focused enough so we submitted something else that was more focused.' Unforeseen requests from the volunteers also required attention. An example was that volunteers wanted designated workspaces, and their own equipment. Non-profit staff had not always thought about the more tangible requirements for volunteers and that took time to learn and fulfill, where possible.

Groupwork Vol. 23(2), 2013, pp.67-87. DOI: 10.1921/3901230201 
Suggestions: In addition to the above themes that emerged from the focus groups, non-profit staff members were interested in, and did offer suggestions for better utilization of their time

A major reason why nonprofit agencies look for volunteers is that they are pressed for time and hope that volunteers might help ease some of that pressure. Their suggestions largely centered on ways to save time in the matching and orientation process, and ultimately at the agency. This included a request for more clarity upfront around what the volunteers were looking for and for ways to be more efficient in training/orientation. From the non-profit agencies' point of view, the purpose of a senior volunteer program is to contribute to agency capacity, and they need to feel that the time expenditure is worthwhile and limited to what is absolutely necessary. In this regard, the non-profit participants expressed feelings of dissatisfaction with the demands of the SmartWorks program. Largely, they thought the program did not fully take into account their needs and was overly focused on those of the volunteers. One area that was commented on was the project proposal format demanded by SmartWorks. Several participants thought that it was overly complicated and required too much detail. One person stated that the agency came close to dropping out of the program because of a formatting issue. Another commented that they too almost left but that they stayed because they wanted volunteers. Project descriptions were expected to be sufficiently descriptive and as one participant added, 'attractive.' That participant said that the agency submitted four proposals but only two were accepted, and it may have been a matter of 'attractiveness.' Another complained about having too much paperwork to fill out for the volunteers in the Smartworks project and one person stated that to require two days of orientation did not seem reasonable, that one half day was more realistic. Finally, on the more positive side, one participant argued for meetings with volunteers and agency staff to smooth out some of these issues.

\section{Discussion and implications}

The implications of this study can be viewed from two perspectives: the challenges and benefits of the volunteer experience for both the senior volunteers and nonprofit staff; and, the use of concurrent, serial focus 
group research. The senior volunteer and nonprofit staff participants in SmartWorks raise a number of issues that are important to note when increasing seniors' civic service opportunities with the nonprofit sector. For one, while the literature (Freedman, 1997; Kovacs \& Black, 1999) addresses the importance of retirees feeling that their work is meaningful, SmartWorks' volunteers emphasized a related dimension of this dialogue - the importance of their ability to learn and expand in new arenas. Meaningful work did not always mean being in a position to utilize the same knowledge and skills in the same ways that they were used in their careers. It often meant being able to apply transferable skills but in areas where they could learn new things and experience new opportunities - both with tasks and with relationships. This is important information in the process of matching volunteers and nonprofit agencies- a process that has become increasingly complex with the varying needs of both volunteers and organizations (Macduff, Netting and O'Connor, 2009).

In addition, SmartWorks volunteers focused on their desire to be well 'used' by the nonprofit organizations. They didn't want to be doing perfunctory tasks but rather saw themselves as giving 100 percent of what they had to offer to the agency. The volunteers in this study were middle-class professionals, used to doing work that required intelligence and initiative, and that is what they expected from their volunteer experience. Sometimes they felt (and the nonprofit agencies agreed) there was confusion about how best to utilize their skills, and so upfront time and ongoing dialogue on skill matching is recommended (Macduff et al, 2009).

The volunteers also valued having SmartWorks as a coordinating/ umbrella agency to help make the linkages and mediate issues that emerged. These types of coordinating organizations can be highly valuable in the recruitment and retention processes necessary to expand a successful movement of civic service for older adults. They also provide a place beyond the non-profit agency itself where volunteers can go for support. Our data show that umbrella organizations can assist nonprofit agencies with matching volunteers with assignments that are of mutual benefit and in the logistical details so that nonprofit staff don't have to learn and implement this all on their own.

If part of the effort to maximize the use of seniors in civic service is to promote capacity of nonprofit agencies, then agency staff would benefit

Groupwork Vol. 23(2), 2013, pp.67-87. DOI: 10.1921/3901230201 
by learning more about the characteristics of senior volunteers, upfront time that may need to be spent in organizing the volunteer's tasks, and the flexibility needed to create something that is ultimately of real value (Hong, Morrow-Howell, Tang and Hinterlong, 2009; Macduff et al, 2008). Administrative social workers have written about the importance and characteristics of successful orientations (Abramson, 1993) and role clarity (Netting, Nelson, Borders and Huber, 2004) that need to be employed in volunteerism. When there is an umbrella organization that provides training in addition to agency orientation, time might be best spent with the two groups (volunteers and nonprofit staff) in dialogue with each other. Cooperative planning would likely enhance the process of matching volunteers with agencies and tasks and project definitions for each agency. When those who will ultimately work together perform this planning, their recommendations for placement and/or training are most likely to result in success on both sides.

The use of concurrent, serial focus groups provided another level upon which to view this project. The concurrent design allowed the researchers to hear the concerns from both sides, the volunteers and the non-profit staff, within a time frame that gave them the opportunity to take action. If the volunteer and nonprofit groups were not concurrent, and if there were fewer of them, this would have placed a limit on the usefulness of the data as a means of improving the project on an on-going basis. The serial nature of the focus groups brought about the unintended consequence of their serving as time-limited support groups. With each cohort of volunteers and agency staff meeting three times in groups, beginning levels of group cohesion and mutual aid were observed.

We think but do not have data to confirm that the volunteers experienced more support from the groups than did the agency staff. Our reason for this supposition is that the volunteers were placed in an unfamiliar environment and the groups served as a place to express their anxieties and share strategies for resolving challenges with other volunteers that they had just met. On the other hand, the agency staff had other colleagues to talk with about their SmartWorks experiences at their respective agencies. Because support and mutual aid was not an intended goal of the project we did not think of testing for this outcome, but would do so in the future. 


\section{Limitations}

As with any qualitative study with limited numbers and a sample that is not representative, the findings have limited generalizability. In addition, this study is based on a sample of older adult volunteers who are largely White, middle class professionals and reside in one medium-sized city in the northeast United States. The expansion of the theory and practice of civic engagement with older adults and the value of running serial concurrent groups with volunteers and agency staff requires data with diverse populations including minorities, those with less financial means and education, and from other geographic areas.

\section{Conclusion}

McBride (2009) states, 'civic engagement is the backbone of the social work profession' (p.295). The SmartWorks program is one example of a program providing civic service opportunities for retired seniors with prior experience as employed professionals. Given the global aging demographics, where older adults are projected for the first time in history to outnumber young children in fewer than ten years (United Nations, 2005), we need to expand our efforts to support healthy as well as frail older adults. Civic engagement opportunities for older adults are one means of addressing healthy retirees' needs. Simultaneously they can also address the needs of frail elders when civic service opportunities are geared towards serving frail elders (Bronstein, McCallion, \& Kramer, 2006; Butler \& Eckart, 2007). Further, the reciprocal value of civic engagement must not be understated; the needs of underfunded nonprofit agencies also benefit when their efforts are geared towards older adults' contributions to their work.

The results of the evaluation of the SmartWorks program from the perspective of both senior volunteers and nonprofits over a two-year period help to expand the knowledge base of the promising practice of civic service. Looking at the mutual benefits for both older adult volunteers and non-profit agencies is critical to our understanding and expansion of civic engagement. This study highlights knowledge for non-profit agencies to think about in recruitment, retention, program design, and implementation of structures that link senior volunteers 
with nonprofit agencies. It supports the need for clarity and support (Marx, 1999; Netting et al, 2004), the importance of the relationship between volunteers and paid workers (Netting et al, 2004), and the role of civic commitment in the volunteer process (Lie et al, 2009). Additionally it lends initial support for the use of serial focus groups as a valuable tool with a range of potential benefits, including evaluation, continuous improvement and mutual aid.

\section{References}

Abramson, J.S. (1993) Orienting social work employees in interdisciplinary settings: Shaping professional and organizational perspectives. Social Work, $38,2,152-157$

Abu-Samah, A. (2009) Empowering research process: Using groups in research to empower the people. in O. Manor (Ed.) Groupwork research. London: Whiting \& Birch (pp.97-128)

Bowen, G.L., Martin, J.A., Mancini, J.A. and Nelson, J.P. (2001) Civic engagement and sense of community in the military. Journal of Community Practice, 9, 2, 71-93

Bronstein, L., McCallion, P. and Kramer, E. (2006) Developing an aging prepared community: Collaboration among counties, consumers, professionals and organizations. Journal of Gerontological Social Work, 48, 1/2, 193-202

Burnette, D., Morrow-Howell, N. and Chen, L. (2003) Setting priorities for gerontological social work research: A national Delphi study. The Gerontologist, 43, 6, 828-838

Butler, S.S. and Eckart, D. (2007) Civic engagement among older adults in a rural community: A case study of the senior companion program. Journal of Community Practice, 15, 3, 77-98

Carlson, C. (2006) The Hampton Experience as a new model for youth civic engagement. Journal of Community Practice, 14, 1, 89-106

Center for Social Development (2008) Civic Engagement and Service: Overview. [ Accessed 15, May, 2012 at http://csd.wustl.edu/CivicEngagementService/ Pages/Overview.aspx]

Chambre, S.M. (1993) Volunteerism by elders: Past trends and future prospects. The Gerontologist, 33, 2, 221-228

Cohen-Callow, A. (2007) Alert! Volunteering probably touches your life. CSWE Gero-Ed Center, Aging Time, 3, 3, 1-3 
A serial focus group model with older adult volunteers and non-profit agency managers

Corporation for National and Community Service (CNCS) (2007) Volunteering in America: 2007 city trends and rankings. Washington, DC: Corporation for National and Community Service, Office of Research and Polity Development Freedman, M. (1999) Prime Time. New York City: Public Affairs

Freedman, M. (1997) Towards civic renewal: How senior citizens could save civil society. Journal of Gerontological Social Work, 28, 3, 243-263

Fried, L.P., Carlson, M., Freedman, M., Frick, K.D., Glass, T.A., Hill, J., McGill, S., Rebok, G., Seeman, T., Tielsch, J., Wasik, B., and Zeger, S. (2004) A social model for health promotion for an aging population: Initial evidence on the Experience Corps model. Journal of Urban Health, 81, 64-78

Gant, L.M., Shimshock, K., Allen-Meares, P., Smith, L, Miller, P., Hollingsworth, L. and Shanks, T. (2009) Effects of photovoice: Civic engagement among older youth in urban communities. Journal of Community Practice, 17, 4, 358-376

Greenfield, E. and Marks, N. (2003) Civic engagement keeps aging Americans mentally healthier after physical decline. Journal of Gerontology, 62B, 1, 13-15

Hinterlong, J. and Williamson, A. (2006) The effects of civic engagement of current and future cohorts of older adults. Generations, 30, 4, 10-17

Hong, S-I., Morrow-Howell, N., Tang, F. and Hinterlong, J. (2009) Engaging older adults in volunteering: Conceptualizing and measuring institutional capacity. Nonprofit and Voluntary Sector Quarterly, 38, 2, 200-219

Huberman, A.M. and Miles, M.B. (1994) Data management and analysis methods. in N. Denzin and Y. Lincoln (Eds.) Handbook of qualitative research. Thousand Oaks, CA: Sage (pp. 428-444)

Institute of Medicine (2001) Crossing the quality chasm: a new health system for the 21 st century. Washington, DC: Institute of Medicine, March

Jirovec, R.L. (2005) Differences in family functioning and health between older adult volunteers and non-volunteers. Journal of Gerontological Social Work, $46,2,23-33$

Kanfer, R., and Ackerman, P.L. (2004) Aging, adult development and work motivation. Academy of Management Review, 29, 3, 440-458

Kovacs, P.J. and Black, B. (1999) Volunteerism and older adults: Implications for social work practice. Journal of Gerontological Social Work, 32, 4, 25-39

Krueger, R.A. and Casey, M.A. (2000) Focus groups, a practical guide for applied research ( $3^{\text {rd }}$ ed.). Thousand Oaks, CA: Sage

Lie, M., Baines, S. and Weelock, J, (2009) Citizenship, volunteering and active ageing. Social Policy and Administration, 43, 7, 702-718

Macduff, N., Netting, F.E. and O'Connor, M.K. (2009) Multiple ways of coordinating volunteers with differing styles of service. Journal of Community Practice, 17, 4, 400-423

Groupwork Vol. 23(2), 2013, pp.67-87. DOI: 10.1921/3901230201 
Martinson, M., and Minkler, M. (2006) Civic engagement and older adults: A critical perspective. The Gerontologist, 46, 318-324

Marx, J. (1999) Motivational characteristics associated with health and human service volunteers. Administration and Social Work, 23, 1, 51-66

McBride, A.M. (2009) Civic Engagement. in T. Mizrahi and L. Davis (Eds.) The Encyclopedia of Social Work (20 th ed.).Vol. 4. New York: Oxford Press and NASW Press (pp. 295-299)

McBride, A.M., Sherraden, M., Benitez, C. and Johnson, E. (2004) Civic service worldwide: Defining a field, building a knowledge base. Nonprofit and Voluntary Sector Quarterly, 33, 4, 8S-18S

McBride, A.M., Sherraden, M. and Menon, N. (2007) Directions in civic service scholarship. in A.M. McBride and M. Sherraden (Eds.) Civic Service Worldwide, Armonk, N.Y: ME Sharpe (pp. 238-253)

McBride, A.M., Sherraden, M., Lombe, M. and Tang, F. (2007) Building knowledge on civic service worldwide. in A.M. McBride and M. Sherraden (Eds.) Civic Service Worldwide, Armonk, N.Y: ME Sharpe (pp. 3-16)

Morrow-Howell, N. (2006) Civic service across the life course. Generations, $30,4,37-42$

Morrow-Howell, N. and Tang, F. (2007). Youth and elder service in comparative perspective. in A. McBride and M. Sherraden, (Eds.) Civic Service Worldwide: Impacts and Inquiry. Armonk, N.Y: ME Sharpe (pp.157-180)

Mulroy, E.A. (2004) University civic engagement with community-based organizations: Dispersed or coordinated models? Journal of Community Practice, 12, 3, 35-52

Narushima, M. (2005) 'Payback time': Community volunteering among older adults as a transformative mechanism. Ageing $\&$ Society, 25, 567-584

Netting, F.E., Nelson, H.W., Borders, K. and Huber, R. (2004) Volunteer and paid staff relationships. Administration and Social Work, 28, 3/4, 69-89

Nicotera, N. (2008) Building Skills for Civic Engagement: Children as Agents of Neighborhood Change. Journal of Community Practice, 16, 2, 221-242

Padgett, D. (2008). Qualitative methods in social work research ( $\left.2^{\text {nd }} e d.\right)$. Los Angeles: Sage

Romero, L. and Minkler, M. (2005) Gold in gray: Senior volunteer leaders as an untapped public health resource. Generations, 29, 2, 36-40

Rosenburg, E. and Letrero, I. (2006) Using age, cohort, and period to study elderly volunteerism. Educational Gerontology, 32, 331-334

Schneider, E.C., Altpeter, M. and Whitelaw, N. (2007) An innovative approach for building health promotion program capacity: A generic volunteer training curriculum. The Gerontologist, 47, 398-403 
Tang, F. and Morrow-Howell, N. (2008) Involvement in voluntary organizations: How adults access volunteer roles? Journal of Gerontological Social Work, 51, 3-4, 210-227

Theiss-Morse, E. and Hibbing, J. R. (2005) Citizenship and civic engagement. Annual Review of Political Science, 8, 1, 227-249

Thompson, E. and Wilson, L. (2001) The potential of older volunteers in longterm care. Generations, 25, 1, 58-63

United Nations Department of Economic and Social Affairs Population Division World Population Prospects (2005) The 2004 Revision. New York: The United Nations

Walton, P. (2009) Focus groups and familiar social work skills: Their contribution to practitioner research. in O. Manor (Ed.) Groupwork Research. London: Whiting \& Birch (pp. 71-85)

Wilson, L. and Rymph, D. (2006). Research issues in civic engagement: Outcomes of a national agenda-setting meeting. in L. Wilson and S. Simson (Eds) Civic Engagement and the Baby Boomer Generation. Binghamton, NY: Haworth Press (pp.195-211)

Windsor, T.D., Anstey, K.J. and Rodgers, B. (2008) Volunteering and psychological well-being among young-old adults: How much is too much? The Gerontologist, 48, 1, 59-70 